\title{
Article \\ A New Computer Model for Evaluating the Selective Binding Affinity of Phenylalkylamines to T-Type $\mathrm{Ca}^{2+}$ Channels
}

\author{
You $\mathrm{Lu}^{1}$ and Ming $\mathrm{Li}^{2, *}$
}

1 Center for Aging, School of Medicine, Tulane University, New Orleans, LA 70112, USA; ylu6@tulane.edu

2 Department of Physiology, School of Medicine, Tulane University, New Orleans, LA 70112, USA

* Correspondence: mli@tulane.edu; Tel.: +1-504-988-8207

check for updates

Citation: Lu, Y.; Li, M. A New Computer Model for Evaluating the Selective Binding Affinity of Phenylalkylamines to T-Type $\mathrm{Ca}^{2+}$ Channels. Pharmaceuticals 2021, 14, 141. https://doi.org/10.3390/ ph14020141

Academic Editor: Osvaldo Andrade Santos-Filho

Received: 27 January 2021

Accepted: 8 February 2021

Published: 10 February 2021

Publisher's Note: MDPI stays neutral with regard to jurisdictional claims in published maps and institutional affiliations.

Copyright: (c) 2021 by the authors. Licensee MDPI, Basel, Switzerland. This article is an open access article distributed under the terms and conditions of the Creative Commons Attribution (CC BY) license (https:/ / creativecommons.org/licenses/by/ $4.0 /)$.
Abstract: To establish a computer model for evaluating the binding affinity of phenylalkylamines (PAAs) to T-type $\mathrm{Ca}^{2+}$ channels (TCCs), we created new homology models for both TCCs and a L-type calcium channel (LCC). We found that PAAs have a high affinity for domains I and IV of TCCs and a low affinity for domains III and IV of the LCC. Therefore, they should be considered as favorable candidates for TCC blockers. The new homology models were validated with some commonly recognized TCC blockers that are well characterized. Additionally, examples of the TCC blockers created were also evaluated using these models.

Keywords: T-type calcium channel blocker; homology modeling; computer-aid drug design; virtual drug screening; L-type calcium channel

\section{Introduction}

As the only type of voltage-gated $\mathrm{Ca}^{2+}$ channels that are activated at or near resting membrane potentials, T-type $\mathrm{Ca}^{2+}$ channels (TCCs) play an important role in regulating $\left[\mathrm{Ca}^{2+}\right]_{\mathrm{i}}$ homeostasis in a variety of tissues, including pancreatic $\beta$-cells and tumor cells [1-4]. Therefore, TCC antagonists could be potentially useful for the treatment of chronic diseases associated with $\mathrm{Ca}^{2+}$ dysregulation [5-7]. For this reason, it is imperative to develop more selective TCC antagonists for prospective clinical applications. Since many existing TCC blockers, such as mibefradil, also show inhibitory effects on L-type calcium channels (LCCs), the most important task in developing new TCC blockers is to enhance their selectivity to TCCs over LCCs. To achieve this, we established TCCphenylalkylamine interaction models based on the specific amino acid sequences in the P-loop of TCCs, and $\alpha_{1}$ C LCCs for characterizing the drug molecules' affinities for TCCs and LCCs, respectively.

TCCs have a close evolutional relationship with LCCs. A recent report from a cryoelectron microscopy study reveals that the frame of the $\alpha_{1} \mathrm{G}\left(\mathrm{Ca}_{\mathrm{v}} 3.1\right)$ pore domain structure is similar to that of $\alpha_{1} S\left(\mathrm{Ca}_{\mathrm{v}} 1.1\right)$ [8]. This similarity allowed us to confidently adopt the global structure of the calcium channel $\mathrm{Ca}_{\mathrm{V}} \mathrm{Ab}$ model, constructed based upon Arcobacter butzleri crystallization [9], in the establishment of our TCC model. One of the most remarkable differences between all types of TCCs and LCCs is a lysine residue located adjacent to the critical glutamic acid/aspartic acid residue in domain III. The existence of a positively charged lysine $\left(\mathrm{K}^{3 \mathrm{p} 49}\right)$ may swing the aspartic acid $\left(\mathrm{D}^{3 \mathrm{p} 50}\right)$ away from the center of the calcium filter and change the preferred calcium ion and drug binding sites from domains III and IV for LCCs to domains I and IV for TCCs. Therefore, we used the ZMM molecule modeling program [10-12] to create four-domain TCC models, in which the binding affinities of drugs to TCCs and $\alpha_{1}$ C LCC were determined by scoring their free energy in binding to the channels [13].

The new TCC models are adopted from a drug-protein interaction framework for modeling $\mathrm{Ca}_{\mathrm{V}} \mathrm{Ab}$ blocking by phenylalkylamines (PAAs) [9]. This is rational because many TCC blockers are PAAs or their derivatives, and because PAAs block $\mathrm{Ca}_{\mathrm{V}} \mathrm{Ab}[9,14]$. 
It is proposed that PAAs bind to LCCs in an inverse V-shaped configuration, with the ammonium group towards the P-helices, and the nitrile group bound to the calcium ion coordinated by the selectivity filter glutamates in domains III and IV of the LCC [15]. We reason that this is also true for TCC blockers, except that the calcium ion is coordinated in the cavity between domains I and IV, since the depolarization confirmed that the pore domains of $\mathrm{Ca}_{\mathrm{V}} 3.1$ and $\mathrm{Ca}_{\mathrm{V}} 1.1$ are superimposed [8]. As a result, the two rings of the flexible PAA molecule [15] will make hydrogen bonding contacts with the mobile side chains of relevant amino acids from domains I and IV of TCCs. This strategy allowed us to create computer models for simulating the interactions between drugs and channel receptors for LCC and TCCs, respectively.

\section{Results}

\subsection{Homology Modeling of TCCs and $\alpha_{1}$ C LCC}

Using the bacterial calcium $\mathrm{Ca}_{\mathrm{v}} \mathrm{Ab}$ open channel 3D structure as the input, $\mathrm{ZMM}$ generated the first template of the calcium channel, which was then modified with S5-Ploop-S6 segments of $\alpha_{1} \mathrm{C}$, and $\alpha_{1} \mathrm{G}, \alpha_{1} \mathrm{H}$, and $\alpha_{1} \mathrm{I}$ (Table 1) to create corresponding protein structures of $\mathrm{Ca}_{\mathrm{v}} 1.2 \mathrm{LCC}$ and $\mathrm{Ca}_{\mathrm{v}} 3.1, \mathrm{Ca}_{\mathrm{v}} 3.2$, and $\mathrm{Ca}_{\mathrm{v}} 3.3 \mathrm{TCC}$, respectively (Figure 1A-D). For cross-validation of ZMM-generated 3D structure models, we also performed ab initio modeling of $\alpha_{1} \mathrm{C}$ and $\alpha_{1} \mathrm{G}$ calcium channels. Since there is a considerable overlap of PAA inhibition between LCC and TCCs [9], the allosteric structures of LCC and TCCs are more likely to be similar. Comparing two different homology modeling tools, ZMM generates more consistent 3D models of the domain III S5-P-loop-S6 segment of $\alpha_{1} \mathrm{C}$ and $\alpha_{1} \mathrm{G}$ (Figure 1E,F) than the ab initio method (Figure 1G,H).

A

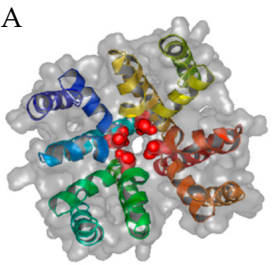

E

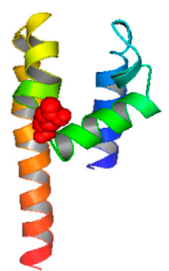

B

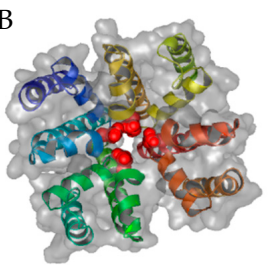

$\mathrm{F}$

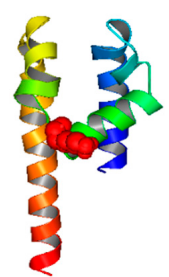

C

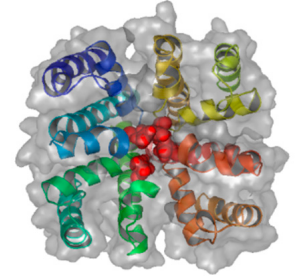

G

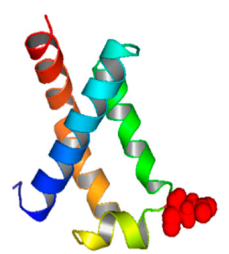

$\mathrm{D}$

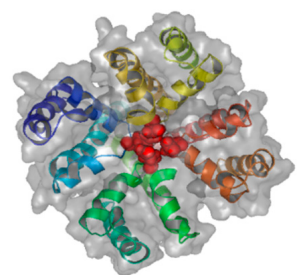

$\mathrm{H}$

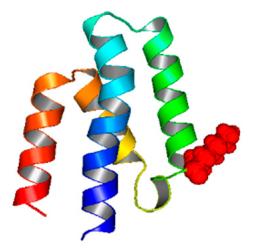

Figure 1. Top views of homology modeling results from ZMM for $\alpha_{1} C, \alpha_{1} G, \alpha_{1} H$, and $\alpha_{1} I$. (A-D) The structures of $\alpha_{1} \mathrm{C}, \alpha_{1} \mathrm{G}, \alpha_{1} \mathrm{H}$, and $\alpha_{1} \mathrm{I}$, respectively; blue, green, brown, and yellow represent domains I, II, III, and IV, respectively; the four selectivity-determining amino acids (glutamic acid or aspartic acid) in the P-loop are colored red and displayed as spheres; ZMM generates more consistent 3D structure than the ab initio modeling method for $\alpha_{1} \mathrm{C}$ and $\alpha_{1} \mathrm{G}$; (E) the predicted 3D structure of the $\alpha_{1} \mathrm{C}$ domain III generated by ZMM, the glutamic acid is represented by red spheres; $(\mathbf{F})$ the predicted 3D structure of the $\alpha_{1} G$ domain III generated by ZMM, the lysine is represented by red spheres; (G) the most representative structure selected by Calibur clustering analysis [16] of $\alpha_{1} \mathrm{C}$ domain III, the glutamic acid is represented by red spheres; $(\mathbf{H})$ the most representative structure selected by Calibur clustering analysis of $\alpha_{1} G$ domain III, the lysine is represented by red spheres.

\subsection{Further P-Loop Remodeling of TCCs}

After determining the globe structure of TCC 3D models, we focused on the variability of the P-loop structure, which is the major drug-ligand interaction segment. The Rosetta P-loop remodeling module [17] was utilized to estimate the variability of P-loop 3D structures on every domain of TCCs. After inputting a perturbation to the original structure, 
the remodeling process was conducted by sampling the possible locations of a given length of an amino acid sequence in three-dimensional space. Using the ZMM generated $\alpha_{1} G$ structure as the reference, the energy-based clustering method [18] was used to determine the P-loop remodeling results with the lowest root-mean-square-displacement (RMSD) score. We found that for $\alpha_{1} \mathrm{G}$, domain II had a clear variation between two different homology modeling methods in sample sizes 500 and 20,000 (Figure 2). It showed that the central P-loop helix segment is in the horizontal position rather than the diagonal position found in other domains. As a result, the selectivity-determining glutamic acids $\mathrm{E}^{2 \mathrm{p} 50}$ may have a larger vertical distance from other glutamic acids / aspartic acids $\left(\mathrm{E}^{1 \mathrm{p} 50}, \mathrm{D}^{3 \mathrm{p} 50}\right.$, and $\left.\mathrm{D}^{4 \mathrm{p} 50}\right)$ in $\alpha_{1}$ G TCCs. This may exclude glutamic acid $\mathrm{E}^{2 \mathrm{p} 50}$ as a $\mathrm{Ca}^{2+}$ binding candidate, leaving the $\mathrm{Ca}^{2+}$ to bind either $\mathrm{E}^{1 \mathrm{p} 50}$ to $\mathrm{D}^{4 \mathrm{p} 50}$ or $\mathrm{D}^{3 \mathrm{p} 50}$ to $\mathrm{D}^{4 \mathrm{p} 50}$ in TCCs. Additionally, to validate the normality of the remodeling data, we conducted a nonparametric test for the $\alpha_{1} G$ P-loop remodeling data and confirmed that all the sampling processes (500 and 20,000) came from the same distribution (see Supplementary Table S2, Supplementary Figure S2 for statistical results).

Table 1. Comparison of numerical results of P-loop electrostatic potential at the four different domains with different lengths of amino acid sequences. TCC: T-type calcium channel.

\begin{tabular}{cccc}
\hline Channel Domain & Channel Type & $\begin{array}{c}\text { AA Sequence } \\
\text { Alignment }\end{array}$ & $\begin{array}{c}\text { PyGBe [19] (Esol, } \\
\text { Ecoul) }\end{array}$ \\
\hline \multirow{3}{*}{ Domain I } & $\alpha_{1}$ G & I T L E G W V D & $-11,-407$ \\
& $\alpha_{1} \mathrm{H}$ & I T L E G W V D & $-110,-408$ \\
& $\alpha_{1}$ I & I T L E G W V E & $-116,-409$ \\
& Reduced TCC & T L E G W V & $-87,-323$ \\
\hline \multirow{5}{*}{ Domain II } & $\alpha_{1}$ G & L T Q E D W N K & $-217,-631$ \\
& $\alpha_{1} \mathrm{H}$ & L T Q E D W N V & $-262,-631$ \\
& $\alpha_{1}$ I & L T Q E D W N V & $-487,-633$ \\
& Reduced TCC & T Q E D W & $-164,-425$ \\
\hline \multirow{5}{*}{ Domain III } & $\alpha_{1}$ G & A S K D G W V D & $-107,-392$ \\
& $\alpha_{1} \mathrm{H}$ & S S K D G W V N & $-113,-425$ \\
& $\alpha_{1}$ I & A S K D G W V N & $-105,-394$ \\
& Reduced TCC & S K D G W & $-101,-303$ \\
\hline \multirow{2}{*}{ Domain IV } & $\alpha_{1}$ G & S T G D N W N G & $-132,-568$ \\
& $\alpha_{1} \mathrm{H}$ & S T G D N W N G & $-164,-574$ \\
& $\alpha_{1}$ I & S T G D N W N G & $-177,-574$ \\
& Reduced TCC & T G D N W & $-86,-393$ \\
\hline
\end{tabular}

2.3. Local Electrostatic Potentials of the Selective P-Loop of TCC Domains and the Impact of $K^{3 p 49}$

A previous study indicated that when a calcium ion enters the selectivity filter region of a LCC, it binds to the selectivity-determining glutamic acids $\left(\mathrm{E}^{3 \mathrm{p} 50}, \mathrm{E}^{4 \mathrm{p} 50}\right)$ in domains III and IV [15]. Consequently, the phenylalkylamine molecules will bind to domains III and IV due to the interaction between the nitrile nitrogen and $\mathrm{Ca}^{2+}$ [15]. In contrast, all TCCs have a lysine $\left(\mathrm{K}^{3 \mathrm{p} 49}\right)$ located at the $5^{\prime}$ end adjacent to $\mathrm{D}^{3 \mathrm{p} 50}$ in domain IIII. It is reported that the replacement of lysine $\left(\mathrm{K}^{3 \mathrm{p} 49}\right)$ with Phe or Gly causes the activation curve to shift to the right [8], which indicates that the lysine in the position adjacent to aspartic acid $\left(\mathrm{D}^{3 \mathrm{p} 50}\right)$ plays a significant role in the kinetic/dynamic mechanism of $\mathrm{Ca}^{2+}$ interaction with the inner environment of the central cavity of TCCs. This positively charged lysine alters the negative charge field distribution of $\mathrm{D}^{3 \mathrm{p} 50}$ to attract $\mathrm{Ca}^{2+}$ (Supplementary Figure S1). It is possible that the lysine $\left(\mathrm{K}^{3 \mathrm{p} 49}\right)$ swings aspartic acid $\left(\mathrm{D}^{3 \mathrm{p} 50}\right)$ away from the original $\mathrm{Ca}^{2+}$ binding position, thus causing the $\mathrm{Ca}^{2+}$ to bind glutamic acid or aspartic acid in other domains, probably to domains I and IV since domain II has a configuration deviation. As a result, the phenylalkylamine may also switch its binding region from domains III and IV to domains I and IV. 

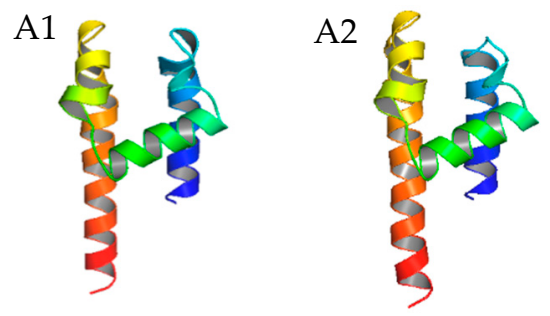

A3

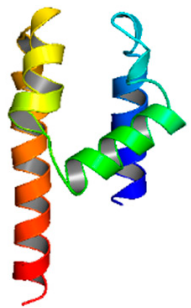

B1

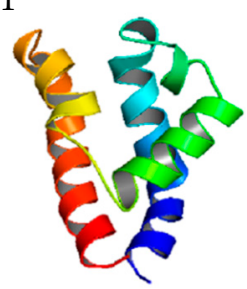

C1

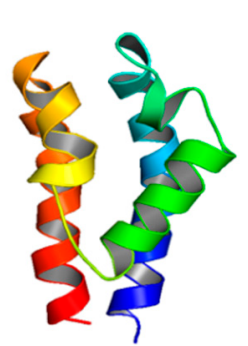

B2

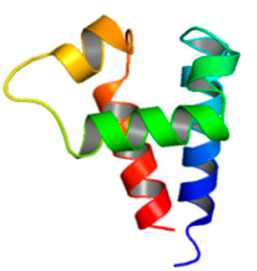

$\mathrm{C} 2$

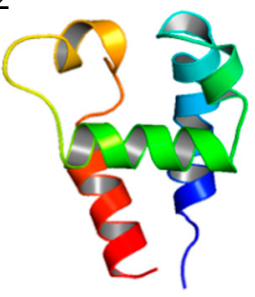

B3

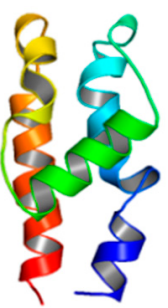

C3

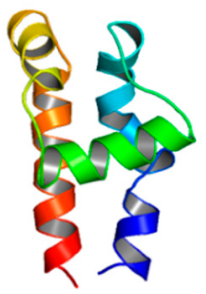

A4

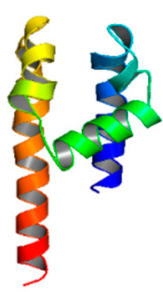

B4

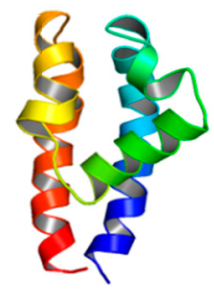

C4

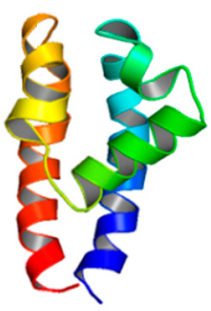

Figure 2. Comparison of the P-loop conformation differences before and after Rosetta P-loop remodeling. (A) Homology modeling of P-loop structures of $\alpha_{1} G$ domain I (A1), domain II (A2), domain III (A3), and domain IV (A4) generated by ZMM; (B) Rosetta P-loop remodeling results of $\alpha_{1} G$ domain I (B1), domain II (B2), domain III (B3), and domain IV (B4) with the sampling size equal to 500; (C) Rosetta P-loop remodeling results of $\alpha_{1} \mathrm{G}$ domain I (C1), domain II (C2), domain III (C3), and domain IV (C4) with the sampling size equal to 20,000.

To determine the effect of lysine $\left(\mathrm{K}^{3 \mathrm{p} 49}\right)$ on overall electrostatic potential (E) for given TCC homology models, we calculated the electrostatic potential (E) for the tailed P-loop of domain I to IV. Table 1 shows that the combined electrostatic potential $\left(\mathrm{E}_{\mathrm{coul}}\right)$ becomes more negative in each domain as the number of testing amino acids is reduced from seven to five. In TCCs, $\mathrm{E}_{\mathrm{coul}}$ for domain I is more negative than that for domain IV in the five amino acid-reduced sequence, indicating a possible switching of the $\mathrm{Ca}^{2+}$ binding site from domains III and IV to domains I and IV.

We used Coulomb's electric force equation to quantitively analyze the influence of lysine on the electrical attraction force between $\mathrm{Ca}^{2+}$ and aspartic acid $\left(\mathrm{D}^{3 \mathrm{p} 50}\right)$. According to the equation in Section 4.2 , lysine $\left(\mathrm{K}^{3 \mathrm{p} 49}\right)$ has the least effect on the $\mathrm{Ca}^{2+}-\mathrm{D}^{3 \mathrm{p} 50}$ attraction when $\mathrm{K}^{3 \mathrm{p} 49}$ is located on the opposite side of the $\mathrm{Ca}^{2+}$ and when $\mathrm{D}^{3 \mathrm{p} 50}$ is at the center. When $a=4.3 \AA$ and $b=3.8 \AA$ [8] (calculated in PyMOL.2.3.3 for ZMM results), Coulomb's force equation (found in Section 4) yields: $\mathrm{F}_{(\mathrm{Ca}, \mathrm{D} \text {, attraction) }}=2.489 \times 10^{-9} \mathrm{~N}$ and $\mathrm{F}_{(\mathrm{Ca}}$, K, repellent) $=$ $0.702 \times 10^{-9} \mathrm{~N}$; thus, lysine, at a minimum, reduces the attraction force between $\mathrm{Ca}^{2+}$ and aspartic acid by more than $28 \%$. The attraction force between $\mathrm{Ca}^{2+}$ and $\mathrm{D}^{3 \mathrm{p} 50}$ will reduce further or reverse into a repellent force as the distance from the $\mathrm{Ca}^{2+}$ to $\mathrm{K}^{3 \mathrm{p} 49}$ decreases; therefore, the preferred binding position of $\mathrm{Ca}^{2+}$ will likely be switched to domains I and IV in TCCs. This limits the PAA binding region on TCCs to domains I and IV. We could use the amino acid structure of domains I and IV to evaluate the affinities of the PAAs (and their derivatives) for TCCs (using models established for $\alpha_{1} G, \alpha_{1} H$, and $\alpha_{1} I$ ) and use the amino acid structure of domains III and IV for evaluating their binding affinities to LCC (using the model of $\alpha_{1} \mathrm{C}$ ). 


\subsection{Model Predictions and Vina Screening Output of Some Current T-Type $\mathrm{Ca}^{2+}$ Channel Blockers}

Mibefradil is reported to have an inhibitory effect on both LCC and TCCs [20]. The $\alpha_{1} \mathrm{C}$ model predicts that one hydrogen atom from the nitrogen $\left(\mathrm{N}_{3}\right)$ on the cyclopentadiene connects to methionine $\left(\mathrm{M}^{4 \mathrm{i} 27}\right)$ on domain IV of $\alpha_{1} \mathrm{C}$ LCC, as shown in Figure 3A,B. This is consistent with the prediction of another model in a previous study [9]. In contrast, the $\alpha_{1} C$ homology model does not predict that hydrogen bonds to NNC 55-0396. NNC 55-0395 inhibits both L- and T-type calcium channels [14]. The $\alpha_{1} \mathrm{C}$ homology model predicts that NNC 55-0395 has one hydrogen bond that connects nitrogen $\left(\mathrm{N}_{3}\right)$ to the glycine $\left(\mathrm{G}^{3 \mathrm{p} 49}\right)$ on P-loop domain IV. For NNC 55-0397, the $\alpha_{1}$ C homology model also predicts that RO 40-5966, a hydrolyzed metabolite of mibefradil [20], has one hydrogen atom from the hydroxy group of the benzene ring bound to the glycine $\left(\mathrm{G}^{4 \mathrm{p} 49}\right)$ at domain IV. No hydrogen bond has been found between the LCC and the TCC blocker SKF-96365.

A

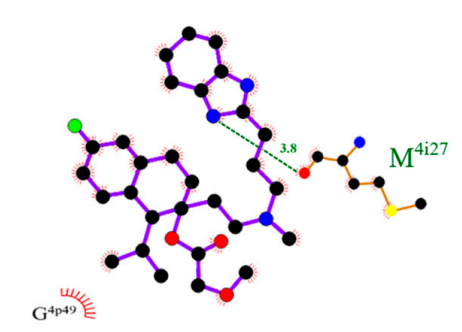

B

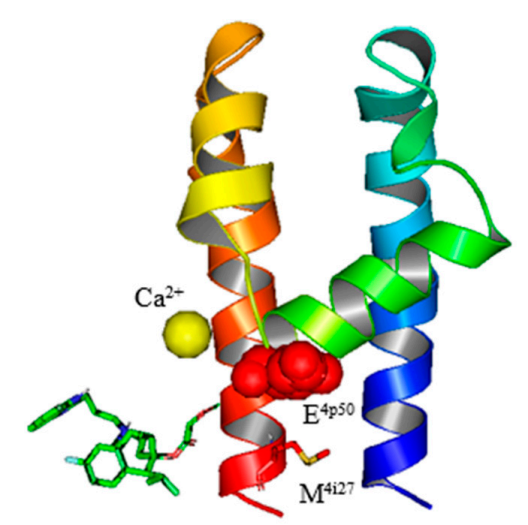

C

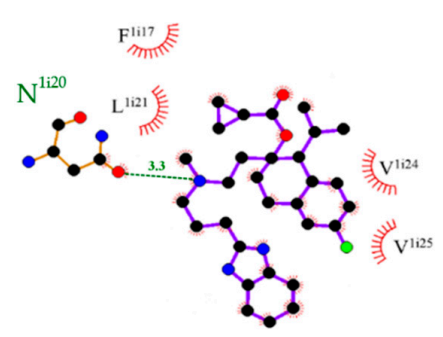

$\mathrm{D}$

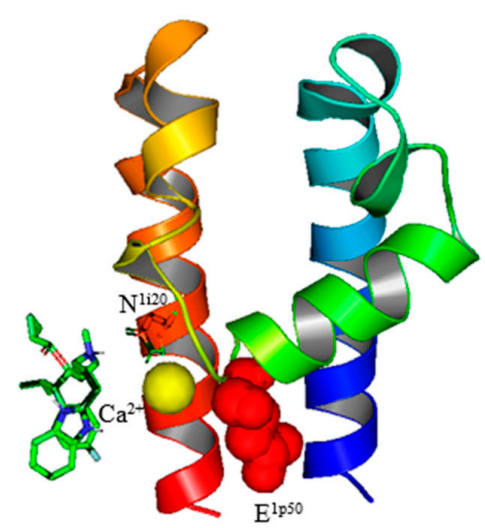

Figure 3. Models of ligand-receptor interactions of mibefradil and NNC 55-0396. (A) The predicted binding sites of mibefradil on $\alpha_{1} \mathrm{C}$. The H-bond formed between the ammonia $\left(\mathrm{N}_{3}\right)$ on the cyclopentadiene of mibefradil and methionine $\left(\mathrm{M}^{4 \mathrm{i} 27}\right)$ on domain IV. The relative locations of surrounding amino acid residues of the $\alpha_{1}$ C L-type calcium channel (LCC) are shown by the arch-dash symbols. (B) The predicted 3D binding sites of mibefradil on $\alpha_{1} \mathrm{C}$ domain IV from a side view. Red spheres represent the position of glutamic acid $\mathrm{E}^{4 \mathrm{p} 50}$. Mibefradil is represented by the green ring structure. (C) The predicted binding sites of NNC 55-0396 on $\alpha_{1}$ G domain IV. The H-bond formed between the central ammonium of NNC 55-0396 and asparagine $\left(\mathrm{N}^{1 \mathrm{i} 20}\right)$ on domain I. (D) The predicted 3D binding sites of NNC 55-0396 on $\alpha_{1}$ G. NNC 55-0396 is represented by the green ring structure. Red spheres represent the position of glutamic acid $\mathrm{E}^{4 \mathrm{p} 50}$. For $\mathrm{A}$ and $\mathrm{C}$, carbon, nitrogen, oxygen, and fluorine elements are represented by black, blue, red, and green, respectively; for B and D, the blue and orange ribbon helices represent S5 and S6, respectively. The ribbon helix structures linking S5 and S6 are P-loops. The yellow ball represents the position of the calcium ion.

Using TCCs as templates, we have revealed some current TCC blockers of $\alpha_{1} G, \alpha_{1} H$, and $\alpha_{1} \mathrm{I}$. The $\alpha_{1} \mathrm{G}$ model predicts that the fluorine atom from the compound NNC 55-0395 forms a halogen bond to glycine $\left(\mathrm{G}^{1 \mathrm{p} 51}\right)$ in domain I. Our $\alpha_{1} \mathrm{G}$ model also predicts a binding site of NNC 55-0396 to asparagine $\left(\mathrm{N}^{\mathrm{li20}}\right)$ in domain I (Figure 3C,D). For NNC 55-0397, the 
fluorine atom from the compound forms a halogen bond with valine $\left(\mathrm{V}^{1 \mathrm{p} 46}\right)$ at the P-loop of domain I. For mibefradil, one oxygen atom from the side chain of the compound forms hydrogen bonds with asparagine $\left(\mathrm{N}^{104}\right)$ at $\mathrm{S} 5$ of domain I. For RO 40-5966, one hydrogen atom from the nitrogen $\left(\mathrm{N}_{3}\right)$ on the cyclopentadiene forms a hydrogen bond with alanine $\left(\mathrm{A}^{1 \mathrm{i} 27}\right)$ in domain I. For SKF-96365, the center oxygen atom forms a hydrogen bond with asparagine $\left(\mathrm{N}^{104}\right)$ at $\mathrm{S} 5$ of domain I.

Our $\alpha_{1} \mathrm{H}$ model predicts that one hydrogen atom from the nitrogen $\left(\mathrm{N}_{3}\right)$ on the cyclopentadiene of NNC 55-0395 interacts with valine $\left(\mathrm{V}^{1 \mathrm{p} 46}\right)$ at the P-loop of domain I to form a bond. The fluorine atom from NNC 55-0396 forms a halogen bond with isoleucine $\left(\mathrm{I}^{1 \mathrm{ii}}\right)$ from the $\alpha_{1} \mathrm{H}$ S6 of domain I. For NNC 55-0397, one hydrogen atom from the nitrogen $\left(\mathrm{N}_{3}\right)$ on the cyclopentadiene forms a bond to asparagine $\left(\mathrm{N}^{4} \mathrm{p} 51\right)$ at the P-loop of domain IV. The hydrogen atom from the nitrogen $\left(\mathrm{N}_{3}\right)$ on the cyclopentadiene of mibefradil finds asparagine $\left(\mathrm{N}^{104}\right)$ to form a bond at S5 of domain I. For RO 40-5966, the fluorine atom from the compound forms a halogen bond with histidine $\left(\mathrm{H}^{4 \mathrm{i} 29}\right)$ at $\mathrm{S} 6$ of domain IV. One oxygen atom from the side chain of SKF-96365 forms a hydrogen bond with asparagine $\left(\mathrm{N}^{104}\right)$ at S5 of domain I.

Our $\alpha_{1} \mathrm{I}$ homology model predicts that NNC 55-0395 forms a halogen bond between the fluorine atom from the compound and isoleucine $\left(\mathrm{I}^{1 \mathrm{li}}\right)$ at $\mathrm{S} 6$ of domain I. The hydrogen atom from NNC 55-0396 forms a bond to asparagine $\left(\mathrm{N}^{104}\right)$ at S5 of domain I. For NNC 55-0397, one hydrogen atom from the nitrogen $\left(\mathrm{N}_{3}\right)$ on the cyclopentadiene interacts with valine $\left(\mathrm{V}^{1 \mathrm{p} 46}\right)$ at the P-loop of domain I to form a bond. For mibefradil, there is a halogen bond formed between a fluorine atom from the compound and a hydrogen atom from asparagine $\left(\mathrm{N}^{4 \mathrm{p} 53}\right)$ at the P-loop of domain IV. For RO 40-5966, one hydrogen atom from the ammonia on the cyclopentadiene interacts with asparagine $\left(\mathrm{N}^{104}\right)$ at $\mathrm{S} 5$ of domain I to form a bond. Our model does not predict the hydrogen bond formed when docking SKF-96365 to $\alpha_{1} \mathrm{I}$.

A comparison of the predicted binding affinity $K_{d}$ and experimental measurements of $\mathrm{IC}_{50}$ for given TCC blockers are listed in Supplementary Table S4. Table 2 summarizes the predicted binding affinity results for all existing TCC blockers.

\subsection{Evaluation of New Compounds}

The Vina [13] models were employed for evaluating the binding affinity of the testing compounds. We randomly selected 300,000 compounds from PubChem and used these as the database to train our recurrent neural networks (RNNs) [21] with the given compound properties.

After performing virtual screening, we found that the compounds TC 7, TC 4, and TC 2 satisfied our screening criteria for $\alpha_{1} G, \alpha_{1} H$, and $\alpha_{1} I$, respectively. Compound TC 7 has the highest binding affinity, as well as a lower (water-octanol partition coefficient) $\log \mathrm{P}$ and a higher Quantitative Estimation of Drug-likeness (QED) than existing TCC blockers. The 3D binding plots between TC 7 and $\alpha_{1}$ G are shown in Supplementary Figure S3. The predicted binding affinities between existing TCC blockers and screened compounds on TCCs and $\alpha_{1}$ C LCC are shown in Figure 4. Our results show that these screened compounds have smaller $\log P$ and Synthetic Accessibility Scores (SAS) but larger QED values than those of selected TCC blockers (as seen in Table 3). More structures and chemical properties for the 13 identified compounds can be found in Supplementary Figures S5-S17. 
Table 2. Predicted Gibbs free energy $\Delta G$ of phenylalkylamines (PAAs) on calcium channels (N/A: not available).

\begin{tabular}{|c|c|c|c|}
\hline Receptor & Drug ID & $\Delta \mathrm{G}(\mathrm{kcal} / \mathrm{mol})$ & Binding Domain \\
\hline \multirow{6}{*}{$\alpha_{1} C$} & NNC 55-0395 & -6.0 & IV \\
\hline & NNC 55-0396 & $\mathrm{N} / \mathrm{A}$ & $\mathrm{N} / \mathrm{A}$ \\
\hline & NNC 55-0397 & -6.4 & IV \\
\hline & Mibefradil & -6.4 & IV \\
\hline & RO 40-5966 & -5.7 & IV \\
\hline & SKF-96365 & $\mathrm{N} / \mathrm{A}$ & IV \\
\hline \multirow{6}{*}{$\alpha_{1} G$} & NNC 55-0395 & -6.5 & I \\
\hline & NNC 55-0396 & -8.1 & I \\
\hline & NNC 55-0397 & -7.4 & I \\
\hline & Mibefradil & -6.8 & I \\
\hline & RO 40-5966 & -7.3 & I \\
\hline & SKF-96365 & -5.6 & I \\
\hline \multirow{6}{*}{$\alpha_{1} \mathrm{H}$} & NNC 55-0395 & -6.6 & I \\
\hline & NNC 55-0396 & -7.7 & I \\
\hline & NNC 55-0397 & -7.0 & IV \\
\hline & Mibefradil & -7.4 & I \\
\hline & RO 40-5966 & -7.4 & IV \\
\hline & SKF-96365 & -5.4 & I \\
\hline \multirow{6}{*}{$\alpha_{1} \mathrm{I}$} & NNC 55-0395 & -6.6 & I \\
\hline & NNC 55-0396 & -7.7 & I \\
\hline & NNC 55-0397 & -7.5 & I \\
\hline & Mibefradil & -6.5 & IV \\
\hline & RO 40-5966 & -6.9 & I \\
\hline & SKF-96365 & $\mathrm{N} / \mathrm{A}$ & $\mathrm{N} / \mathrm{A}$ \\
\hline
\end{tabular}

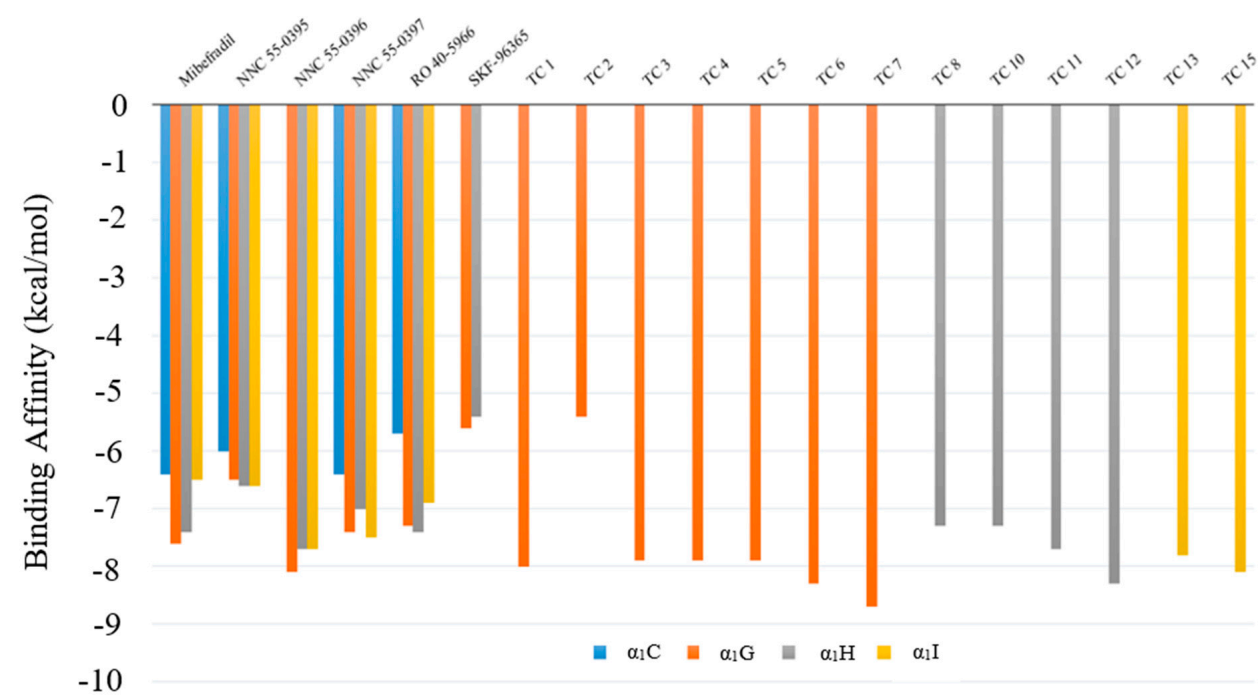

Figure 4. Predicted Gibbs free energy of select T-type $\mathrm{Ca}^{2+}$ channel (TCC) blockers and computerdesigned compounds of different receptors. Blue $-\alpha_{1} \mathrm{C}$, brown $-\alpha_{1} \mathrm{G}$, gray $-\alpha_{1} \mathrm{H}$, and yellow $-\alpha_{1} \mathrm{I}$. 
Table 3. The chemical properties of computer-designed compounds and selected TCC blockers. SAS: Synthetic Accessibility Scores, QED: Quantitative Estimation of Drug-likeness.

\begin{tabular}{|c|c|c|c|}
\hline Compound Name & $\log P$ & SAS & QED \\
\hline NNC 55-0365 & 6.8147 & 3.678636 & 0.273518 \\
\hline NNC 55-0396 & 6.0345 & 3.716436 & 0.351695 \\
\hline NNC 55-0397 & 6.2805 & 3.718535 & 0.337773 \\
\hline Mibefradil & 5.2709 & 3.71918 & 0.367183 \\
\hline TC 1 & 6.1671 & 4.433975 & 0.402836 \\
\hline TC 2 & 5.3351 & 5.24865 & 0.408449 \\
\hline TC 3 & 4.8963 & 4.777741 & 0.474028 \\
\hline TC 4 & 5.0404 & 4.731275 & 0.441386 \\
\hline TC 5 & 5.5879 & 4.951457 & 0.415026 \\
\hline TC 6 & 4.4585 & 4.79633 & 0.469604 \\
\hline TC 7 & 3.6902 & 4.806084 & 0.63381 \\
\hline TC 8 & 6.2697 & 4.851381 & 0.242332 \\
\hline TC 10 & 4.1891 & 4.542497 & 0.312353 \\
\hline TC 11 & 5.372 & 3.089346 & 0.276759 \\
\hline TC 12 & 4.9472 & 3.971406 & 0.248549 \\
\hline TC 13 & 5.7028 & 4.449589 & 0.406663 \\
\hline TC 15 & 4.73 & 3.921747 & 0.368816 \\
\hline
\end{tabular}

\section{Discussion}

A TCC ( $\left.\mathrm{Ca}_{\mathrm{v}} 3.1\right) 3 \mathrm{D}$ structure has already been modeled with cryo-electron microscopy [8]; however, this structure is constructed based on a splice variant containing a deletion of 133 amino acids within the I-II linker. Electrophysiological characterization of these variants $\left(\mathrm{Ca}_{\mathrm{v}} 3.1-\Delta 8 \mathrm{~b}\right)$ shows 1.5-2-fold conductance increases when compared with the full-length form in human and rat preparations. Both activation and steady-state inactivation curves are shifted in the human preparation [8]. In addition, the pore diameter estimated from $\mathrm{Ca}_{\mathrm{v}} 3.1-\Delta 8 \mathrm{~b}$ is smaller than the biophysical measurement [8]. These alterations in TCC electrophysiological properties suggest that the conformation of the cryo-electron microscopy structure is not the same as the full-length $\mathrm{Ca}_{\mathrm{v}} 3.1$ TCC. Therefore, the $3 \mathrm{D}$ structure of $\mathrm{Ca}_{\mathrm{v}} 3.1-\Delta 8 \mathrm{~b}$ may not be the most suitable template for the general modeling of TCCs, especially for PAA binding, which is highly dependent on the position of $\mathrm{Ca}^{2+}$ interacting with the selectivity filter of TCCs. In this study, we chose to use $\mathrm{Ca}_{\mathrm{v}} \mathrm{Ab}$ as the model template since this channel is blocked by PAA and therefore is suitable for establishing a model for evaluating PAAs that inhibit TCCs selectively over LCCs.

Increasing evidence indicates the pathological role of TCCs in the progression of different diseases [6]. It is crucial to develop selective TCC blockers to establish new treatments for these diseases. Unfortunately, lacking the TCC X-ray crystallization structure hampers the progress of creating new TCC blockers. In practice, it is very difficult to find or design a compound that selectively blocks TCCs but not LCCs, since most current TCC blockers exhibit a certain level of inhibitory effects on LCCs. For example, mibefradil, the first launched TCC inhibitor, was quickly recognized to cross inhibit LCC [20]. Here, we provide a new strategy by which the specificity of candidate compounds for binding TCCs but not LCCs can be pre-screened with new computer-based models. This is desirable for designing and developing compounds that more selectively block TCCs than LCCs.

We chose to build models for the interaction between TCCs and PAAs since the binding mechanism of these compounds to LCCs has been studied extensively $[9,15,22-26]$. Based upon the critical single amino acid lysine $\left(\mathrm{K}^{3 \mathrm{p} 49}\right)$ difference between LCCs and TCCs, 
we have created a strategy that can distinguish the affinity of PAAs to TCCs and LCCs, respectively. The models have been validated by measuring the affinities of existing TCC blockers to LCCs and TCCs. We also used these models for evaluating the specificities of novel PAAs and phenylalkylamine derivatives in terms of their binding affinities to TCCs and LCCs.

Using ZMM, we simultaneously created $\alpha_{1} \mathrm{G}, \alpha_{1} \mathrm{H}$, and $\alpha_{1} \mathrm{I}$ TCC and $\mathrm{a}_{1} \mathrm{C}$ LCC structures with four domains, each containing three segments: segment 5, a P-loop, and segment 6. In contrast, the ab initio modeling method failed to produce a suitable calcium channel structure compared to ZMM.

The selectivity of the calcium channel is dependent on the critical glutamate residues located in the selectivity filter of the P-loop of the $\alpha_{1}$ subunit in each domain. In this region, there are two negatively charged glutamic acid residues likely to attract one $\mathrm{Ca}^{2+}$ in the space close to domains III and IV [15]. When a phenylalkylamine molecule approaches a calcium channel from the cytoplasmic side, its nucleophilic nitrile nitrogen reaches the $\mathrm{Ca}^{2+}$, while the other parts of the molecule form affiliated interactions with the amino acids in the P-loop and segments 5 and 6 in domains III and IV of the calcium channel. This causes a physical blockage of ion flow through the channel. In the case of TCCs, there is a lysine $\left(\mathrm{K}^{3 \mathrm{p} 49}\right)$ located adjacent to $\mathrm{D}^{3 \mathrm{p} 50}$ in domain III, and the ionized electric potential distribution of the aspartic acid is altered by lysine, which attenuates the electric attraction of aspartic acid $\left(\mathrm{K}^{3 \mathrm{p} 49}\right)$ to $\mathrm{Ca}^{2+}$ at the minimum binding distance ( 4.3 angstroms) and may swing $\mathrm{K}^{3 \mathrm{p} 49}$ away from the selectivity filter. Based on this analysis, we suggest that $\mathrm{Ca}^{2+}$ will not bind to domain III but to domain I of TCCs. This prediction is consistent with the $\mathrm{Ca}_{\mathrm{v}} 3.1$ structure estimated with cryo-electron microscopy [8], which showed the electron density of the top $\mathrm{Ca}^{2+}$ ion is closest to Glu354 of $\mathrm{Ca}_{\mathrm{v}} 3.1$ ( $\mathrm{E}^{1 \mathrm{p} 50}$, Table 4). Additionally, Rosetta P-loop remodeling shows that the P-loop of domain II is in a more horizontal confirmation than that of other domains, rendering the glutamic acid $\left(\mathrm{E}^{2 \mathrm{p} 50}\right)$ further away from the $\mathrm{Ca}^{2+}$ binding site. Since the movements of PAAs will follow the location of $\mathrm{Ca}^{2+}$ docking, our models are built for evaluating the affinity of candidate compounds binding to domains I and IV. The compounds that are predicted to have a higher affinity to bind domains I and IV of TCCs but not domains III-IV of LCC $\left(\alpha_{1} C\right)$ are considered to be ideal selective TCC blocker candidates. This strategy screens out the compounds that are unlikely to bind LCC and TCCs as well as the compounds that are likely to bind both LCC and TCCs. To test whether $\mathrm{Ca}^{2+}$ docking is consistent on domains I and II across different TCCs, a molecular dynamics study should be conducted with modified membrane conditions and simulation environments [27]. 
Table 4. Amino acid sequences of $\alpha_{1} G$ used for searching the homology modeling template.

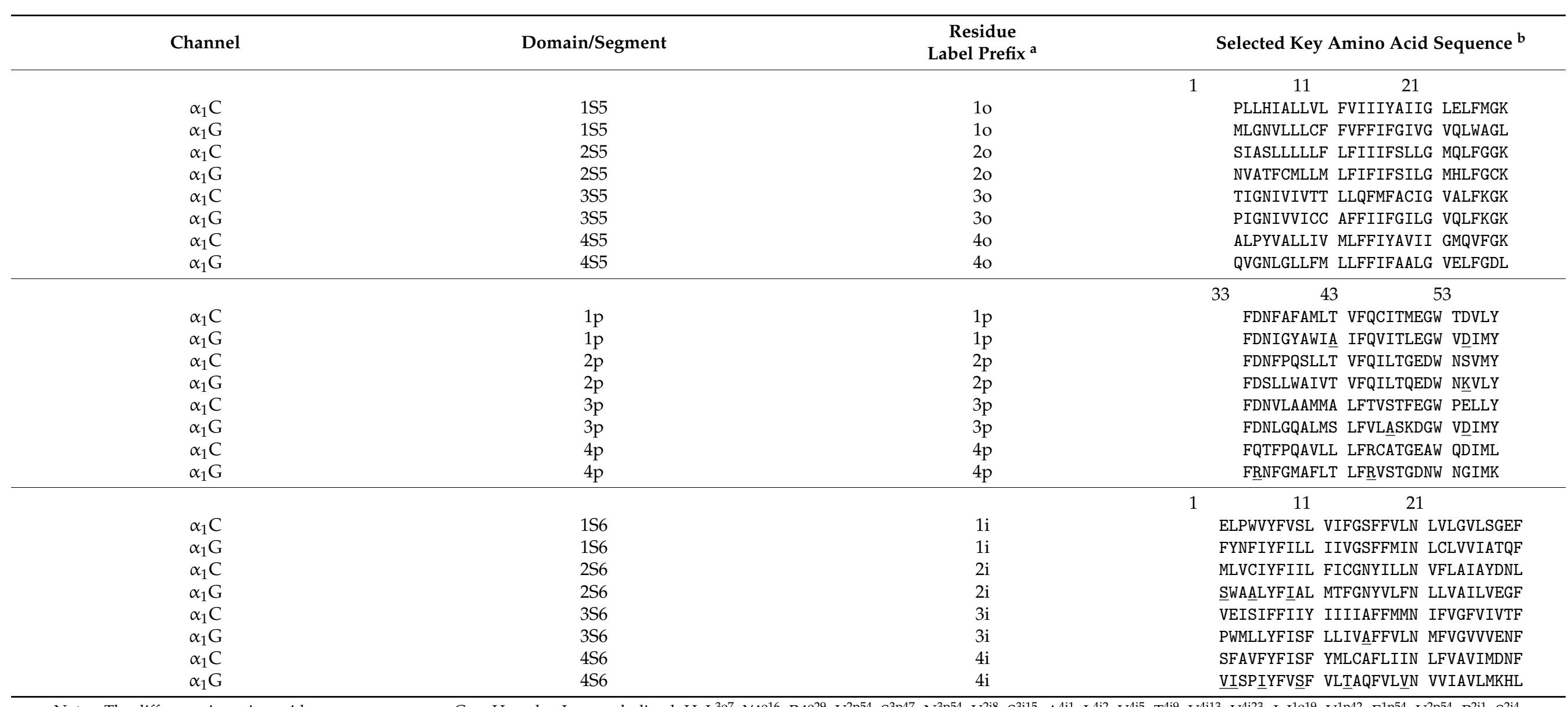

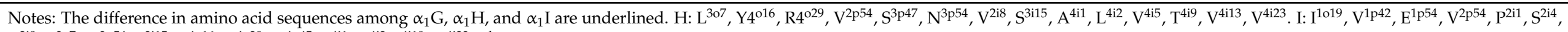

$\mathrm{V}^{2 \mathrm{ii}}, \mathrm{L}^{307}, \mathrm{~N}^{3 \mathrm{p} 54}, \mathrm{~S}^{3 \mathrm{i} 15}, \mathrm{Y}^{4016}, \mathrm{~K}^{4029}, \mathrm{Q}^{\mathrm{4p} 45}, \mathrm{~F}^{4 \mathrm{i1}}, \mathrm{V}^{4 \mathrm{i2}}, \mathrm{I}^{4 \mathrm{i} 19}, \mathrm{~V}^{4 \mathrm{i} 23}$. a,b Residue sequences are labeled according to the alignment of the outer helix, the P-loop, and the inner helix of the KcsA structure [15]. 
Previous studies suggest that the nitrile and isopropyl groups in devapamil and some other PAAs serve to guide the drug to the position of $\mathrm{Ca}^{2+}$; this function persists if the nitrile is replaced with other elements with high electronegative potentials, such as oxygen or sulfur [15]. In many molecules discussed here, including mibefradil, the nitrile is replaced with a methoxy acetyl side chain or a similar side chain with a high electronegative potential. These molecules behave presumably like those of molecules with nitrile in their alkaline chain. Some of the molecules, such as RO 40-5966 and SKF-96365, do not share the binding mechanism described by our model, and therefore their inhibitory effects on $\mathrm{Ca}^{2+}$ channels may not be explained by our new models. For example, by using the input template SKF-96365, we obtained 14 unique structures (as seen in Supplementary Table S3, Figure S4), which had negative binding affinities to our TCC models.

Although our models are designed to select compounds that are likely to bind domains I and IV of TCCs, this does not exclude the possibility that PAAs or their derivatives might inhibit TCCs via binding to domains I and II, domains II and III, or even domains III and IV. The goal of our models was to increase the likelihood of success in screening selective TCC blockers based on their chemical structures.

Our $\alpha_{1} \mathrm{C}$ model has a similar channel pore size (selectivity filter region) as $\mathrm{Ca}_{\mathrm{v}} \mathrm{Ab}[9]$; however, $\alpha_{1} \mathrm{G}, \alpha_{1} \mathrm{H}$, and $\alpha_{1} \mathrm{I}$ may have smaller diameters than $\mathrm{Ca}_{\mathrm{v}} \mathrm{Ab}$, since the unitary conductance of TCC currents is smaller than that of LCC. Further statistical analyses of P-loop remodeling data show that a minimal structural difference exists in the P-loop region remodeling data (see Supplementary Materials for details of the statistical analysis).

The Vina screening results of $\alpha_{1} \mathrm{C}$ identify no binding location for NNC 55-0396 or SKF-96365. The predicted $\alpha_{1} \mathrm{C}$ binding amino acid for NNC 55-0397, as well as mibefradil, matches the experimental results, which show the inhibitory effect of NNC 55-0397 and mibefradil on LCCs. Although RO 40-5966 has a lower $\Delta \mathrm{G}$ than mibefradil when binding to $\alpha_{1} \mathrm{C}$, the predicted binding location is closer to the center of the channel filter region than mibefradil, which indicates a stronger blocking effect on the rate of $\mathrm{Ca}^{2+}$ influx than mibefradil.

Although the $\mathrm{K}_{\mathrm{d}}$ values predicted by Vina have some gaps compared to the experiment data, they do follow the same order of magnitude (Supplementary Table S4). To obtain a more accurate Gibbs free energy for PAAs binding to TCCs, at least two consecutive steps must be conducted: first, the flexible docking process [28]; second, the free energy calculation between ligand and receptor [29]. These two steps require an extensive computational cost and the final $\mathrm{K}_{\mathrm{d}}$ value is very sensitive to the initial input of the receptor structures. Recently deposited human $\alpha_{1} G$ structures offer a good template for developing TCC blockers [8]; however, they have some uncommon regions missing, which could affect PAA binding. Therefore, we argue that it is less likely that the Gibbs free energy of mibefradil/NNC 55-00396 between the prediction and the experiment is matched by choosing different docking programs or conducting a molecular dynamics simulation to find the free energy.

Our work only focuses on the first step of the drug development process in silico, providing a strategy for predicting the comparative potency of candidate compounds to TCCs versus LCCs. Neither are used for evaluating the pharmacological effects of these compounds on other types of cation channels. Since the strength of the pharmacological effects of PAAs and their derivatives on blocking calcium channels are increased by the appearance of a calcium cation in the channel pore [15], it is unlikely that these PAAs and their derivatives will exhibit a strong inhibitory effect on other cation channels.

\section{Materials and Methods}

\subsection{Homology Modeling of the $\alpha_{1}$ Subunit}

Three classes of calcium channel families have been discovered: $\mathrm{Ca}_{V} 1 . \mathrm{X}, \mathrm{Ca}_{\mathrm{V}} 2 . \mathrm{X}$, and $\mathrm{Ca}_{V} 3 . X$. The $\mathrm{X}$ represents the subdivisions of the sequence homology of the $\alpha_{1}$ subunit in each class. The models of drug-channel interactions built upon the structural differences in the relevant S5, P-loop, and S6 regions of $\alpha_{1} G, \alpha_{1} H, \alpha_{1}$ I TCCs, and $\alpha_{1}$ C LCC, respectively. 
The protein templates were obtained from BAM [30] using truncated inputs of human $\alpha_{1} G$, $\alpha_{1} \mathrm{H}, \alpha_{1} \mathrm{I}$, and $\alpha_{1} \mathrm{C}$ (UniProt id: O43497) amino acid sequences (see Table 4 for details). The crystallization structure (PDB id: $5 \mathrm{kmh}$ ) for the depolarization status of the calcium channel protein, originally extracted from Arcobacter butzleri [9], was employed as the structure template of our model. The multi-domain protein structures of human $\alpha_{1} \mathrm{G}, \alpha_{1} \mathrm{H}$, $\alpha_{1} \mathrm{I}$, and $\alpha_{1} \mathrm{C}$ were built using the ZMM molecular modeling software. The forcefield of specific amino acids was simulated by using the Assisted Model Building with Energy Refinement (AMBER) program. The final structure of the target peptides was optimized by using the Monte Carlo minimization protocol. The maximum iteration time for finding the global minimum was set to 5000. During the energy optimization, structural similarity between target and template was maintained by a flat-bottom parabolic energy penalty function that allows for penalty-free deviations of alpha-carbons up to 1 atom distance from their respective positions in the template, and a penalty was imposed with a force constant of $10 \mathrm{kcal} \mathrm{mol-1A}-2$ for larger deviations [15]. The homology models for human $\alpha_{1} \mathrm{H}$ (UniProt id: O95180), $\alpha_{1} \mathrm{I}$ (UniProt id: Q9P0X4), and $\alpha_{1} \mathrm{C}$ (UniProt id: Q13936) were also built with this method.

\subsection{Local Electrostatic Potential Calculation}

To calculate the electric double layer-related local electrostatic potential while a channel protein interacted with a surrounding water molecule, we generated the corresponding meshes using MSMS (v2.6.1) [31] and set the probe radius to 1.4 and the density to 3.0 for quality control. For truncated amino acid sequences, the local electrostatic potential/binding energy is derived from the summation of the solvation energy and Coulomb energy, i.e., $G_{\text {complex }}=G_{\text {solution }}+G_{\text {Coulomb }}$. The $G_{\text {Coulomb }}$ for LCC and TCCs in the P-loop region was calculated by using PyGBe with pre-defined parameters (Supplementary Table S1). To compare the influence provided by a single lysine, we used Coulomb's law to calculate the electric attracting force between $\mathrm{Ca}^{2+}$ and aspartic acid:

$$
\mathrm{F}_{(\mathrm{Ca}, \mathrm{D})}=\mathrm{k}_{\mathrm{e}} \frac{\mathrm{q}_{\mathrm{Ca}} \mathrm{q}_{\mathrm{D}}}{\mathrm{a}^{2}},
$$

where $\mathrm{k}_{\mathrm{e}}$ is Coulomb's constant $8.99 \times 109 \mathrm{~N} \cdot \mathrm{m}^{2} \cdot \mathrm{C}^{-2}$; $\mathrm{a}$ is the distance between $\mathrm{Ca}^{2+}$ and aspartic acid; $\mathrm{q}$ is the point charge for $\mathrm{Ca}^{2+}$, aspartic acid (D), and lysine $(\mathrm{K})$, respectively. The effect of the repellent force on $\mathrm{Ca}^{2+}$ by lysine in the direction of the $\mathrm{Ca}^{2+}$ and the aspartic acid attracting force is defined by

$$
\mathrm{F}_{(\mathrm{Ca}, \mathrm{K})}=\mathrm{k}_{\mathrm{e}} \frac{\mathrm{q}_{\mathrm{Ca}} \mathrm{q}_{\mathrm{K}}}{\mathrm{r}^{2}} \cdot \cos \theta,
$$

where $\theta$ is the angle between the lines from $\mathrm{Ca}^{2+}$ to aspartic acid and from $\mathrm{Ca}^{2+}$ to lysine; $\mathrm{r}$ is the distance between $\mathrm{Ca}^{2+}$ and lysine, which is calculated by

$$
r=a \cdot \cos \theta \pm \sqrt{b^{2}-(a \cdot \sin \theta)^{2}}
$$

where $b$ is the distance from aspartic acid to lysine. When the angle between $\mathrm{Ca}^{2+}$ and aspartic acid, and lysine and aspartic acid $(\phi)$ is less than $90^{\circ}, \mathrm{r}=\mathrm{a} \cdot \cos \theta+\sqrt{\mathrm{b}^{2}-(\mathrm{a} \cdot \sin \theta)^{2}}$; when $\phi$ is equal to $90^{\circ}, \mathrm{r}=\mathrm{a} \cdot \cos \theta$; when $\phi$ is larger than $90^{\circ}, \mathrm{r}=\mathrm{a} \cdot \cos \theta-\sqrt{\mathrm{b}^{2}-(\mathrm{a} \cdot \sin \theta)^{2}}$. Therefore, the electric force between $\mathrm{Ca}^{2+}$ and aspartic acid is

$$
\mathrm{F}_{(\mathrm{Ca}, \mathrm{D}, \mathrm{K})}=\mathrm{F}_{(\mathrm{Ca}, \mathrm{D})}-\mathrm{F}_{(\mathrm{Ca}, \mathrm{K})}=\mathrm{k}_{\mathrm{e}} \frac{\mathrm{q}_{\mathrm{Ca}} \mathrm{q}_{\mathrm{D}}}{\mathrm{a}^{2}}-\mathrm{k}_{\mathrm{e}} \frac{\mathrm{q}_{\mathrm{Ca}} \mathrm{q}_{\mathrm{K}}}{\mathrm{r}^{2}} \cdot \cos \theta .
$$

\subsection{Ab Initio Modeling}

The ab initio modeling modules from Rosetta were employed to find the threedimensional structure of target fragmental peptides by sampling and assembling a large 
candidate pool containing 22,000-27,000 decoy structures for every inputted amino acid sequence [32]. The output results of ab initio modeling were analyzed using the Calibur and energy-based clustering methods.

\subsection{P-Loop Remodeling}

The P-loop region of $\alpha_{1} G$ was remodeled using a Rosetta loop modeling module combined with the FastRelax protocol. Twenty-seven amino acids in the P-loop were selected from domains I, II, III, and IV of the TCCs. The modeling used phenylalanine as the starting amino acid and tyrosine, tryptophan, proline, and isoleucine as the ending amino acids. The effective sample size used for subsequent statistical analysis was validated by two groups of data for every remodeled domain. The first group contained 500 output structures, and the second group had 20,000 output structures. The results were analyzed using the Calibur and energy-based clustering methods.

\subsection{Compound Generation}

We used the de novo drug generation package "chemical vae" developed by GomezBombarelli et al. [21] to create a data-driven RNN for new compound production. The dataset we used to train the RNN was prepared by randomly sampling approximately 250,000 compounds from PubChem. The maximum length of encoding for the SMILES-based compounds was set to 120 characters. To analyze the compounds using the RNN, one fully connected layer of width 200 was used. To convert a predicted compound back to the original data type, three layers of gated recurrent units with a hidden dimension of 500 were used. The variational loss of the RNN was annealed according to a sigmoid schedule after 35 epochs, running for 130 epochs while property prediction training the RNN, such that the RNN trained on the PubChem data set with objective properties including: $\log P$, SAS [33], and QED [34]. We kept the other hyperparameters to train the RNN unchanged from the reference [21]. To transfer the predicted compound back to SMILES-based data, we set the Gaussian noise value to 5 and the iteration time to 1000 . Once the 2D structure had been obtained, we converted it into a 3D structure via the online program Frog $2.1[35,36]$. The program OpenBabel 2.4.1 [37] was used to add the hydrogen atom and set the $\mathrm{pH}$ equal to 7.35 for select compounds.

The 2D structure of mibefradil was employed as a redesigned template for new compounds. Based on its structure, we recreated 129 PAAs and their derivatives. Their corresponding 3D structures (involving up to 800 isomers) were created by Frog 2.1. We used the same program to find the 3D structures for NNC 55-0395, NNC 55-0396, and NNC 55-0397, and combined them with SKF96365 and RO 40-5966, whose 3D structures were downloaded from PubChem, for use as reference compounds for testing and validating the faithfulness of our TCC models.

Some of the candidates of screening compounds may contain oxygen, which replaces the role of nitrile; this structural formula has been reported in certain PAAs such as falipamil, BRL-32872, and tiapamil [15].

\subsection{Virtual Drug Screening}

Virtual drug screening was conducted by using AutoDock Vina [13] with user-defined configuration scripts on the Tulane supercomputer Cypress. The search box was placed in the center of the protein model. The number of mesh elements in the $\mathrm{X}, \mathrm{Y}$, and $\mathrm{Z}$ directions was set to 60,124 , and 102 for $\alpha_{1} C$ and 58,48 , and 50 for $\alpha_{1} G, \alpha_{1} H$, and $\alpha_{1} I$, respectively, when simulating the ligand-receptor interaction for existing TCC blockers. The number of mesh elements in the X, Y, and Z directions was increased to 126 when conducting virtual screening for newly designed compounds. To achieve repeatable docking results using Vina, the seed number was fixed at -1460306363 . As the grid number for every direction was set to the maximum, Vina had to search a very large three-dimensional space. To find the local minimum, the exhaustiveness was set to 2000 for new compound screening cases and 8 for existing TCC blocker screening cases. The number of predictable binding models 
expressed as the output was limited to 3 for new compound screening cases and 20 for existing TCC cases.

The Vina output results were checked using PyMOL to ensure the binding locations for existing and newly designed compounds. The predicted binding affinity for the testing compound was calculated as:

$$
\mathrm{K}_{\mathrm{d}}=\exp \left(\frac{-\Delta \mathrm{G} \cdot \mathrm{kcal} \cdot \mathrm{mol}^{-1}}{0.001986 \cdot \mathrm{kcal} \cdot \mathrm{mol}^{-1} \cdot \mathrm{K}^{-1} \cdot 310 \mathrm{~K}}\right),
$$

where $\Delta \mathrm{G}$ is the Gibbs free energy predicted by Vina.

The 2D ligand-receptor interaction plot was created using LigPlot ${ }^{+}$[38].

\subsection{Data Analysis}

The Anderson-Darling normality test and the Kruskal-Wallis one-way ANOVA test (Supplementary Table S2) were conducted on the generated homology modeling data from Rosetta ab initio modeling and P-loop remodeling in Anaconda Spyder (3.2.8) using a Python 3.6 environment.

\section{Patents}

All the new identified compounds in this study are patented by the Office of Technology Transfer and Intellectual Property Development at Tulane University (Patent ID: US62/859,519).

Supplementary Materials: The following are available online at https:/ /www.mdpi.com/1424-824 $7 / 14 / 2 / 141 /$ s1. Figure S1. The negatively charged lysine affects the electric potential distribution of aspartic acid in the $x-y$ plane. (A) The Dist. of $E_{D}(0,0)$ without $K$; (B) the Dist. of $E_{D}(0,0)$ after adding the lysine $\mathrm{E}_{\mathrm{K}}(3.8,0)$, Figure $\mathrm{S} 2$. The predicted versus theoretical RMSD plots for group sampling size 500 and 20,000. (A,B,C,D) Domains I to IV for 500 sampling size group; (E,F,G,H) Domains I to IV for 20,000 sampling size group Figure S3. The predicted 3D binding plots between TC 7 and $\alpha_{1}$ G. An alkyl bond (4.31 angstroms) has been formed between TC 7 (green) and the sidechain of $\mathrm{V}^{1 \mathrm{i} 24}$ (red) at domain I. The sidechain of $\mathrm{E}^{1 \mathrm{p} 50}$ is colored as blue and one $\mathrm{Ca}^{2+}$ is colored as yellow; Figure S4. Based on the 2D structure of SKF-96365, 10 structures have been found using the Deep-Learning based de novo drug design approach, Figure S5. 2D structure and chemical properties of the redesigned phenylalkylamine analog, TC 1, Figure S6. 2D structure and chemical properties of the redesigned phenylalkylamine analog, TC 2, Figure S7. 2D structure and chemical properties of the redesigned phenylalkylamine analog, TC 3, Figure S8. 2D structure and chemical properties of the redesigned phenylalkylamine analog, TC 4, Figure S9. 2D structure and chemical properties of the redesigned phenylalkylamine analog, TC 5, Figure S10. 2D structure and chemical properties of the redesigned phenylalkylamine analog, TC 6, Figure S11. 2D structure and chemical properties of the redesigned phenylalkylamine analog, TC 7, Figure S12. 2D structure and chemical properties of the redesigned phenylalkylamine analog, TC 8, Figure S13. 2D structure and chemical properties of redesigned phenylalkylamine analog, TC 10, Figure S14. 2D structure and chemical properties of the redesigned phenylalkylamine analog, TC 11, Figure S15. 2D structure and chemical properties of the redesigned phenylalkylamine analog, TC 12, Figure S16. 2D structure and chemical properties of the redesigned phenylalkylamine analog, TC 13, Figure S17. 2D structure and chemical properties of the redesigned phenylalkylamine analog, TC 15. Table S1. Numerical parameter settings for running PyGbe, Table S2. Normality test for P-loop remodeling data $\left(\alpha_{1} G\right)$ from two groups with different sampling sizes, Table S3. The structures and properties of computer-designed compounds using Deep-Learning (D: distance; C: count; F: frequency). Table S4. Predicted binding affinity $\left(\mathrm{K}_{\mathrm{d}}\right)$ by Vina versus experimental measurement of $\mathrm{IC}_{50}$ of given TCC blockers (unit: micromolar).

Author Contributions: Conceptualization, Y.L. and M.L.; methodology, Y.L. and M.L.; software, Y.L.; validation, Y.L. and M.L.; formal analysis, Y.L.; investigation, Y.L.; resources, Y.L.; data curation, Y.L.; writing-original draft preparation, Y.L.; writing—review and editing, Y.L. and M.L.; visualization, Y.L.; supervision, M.L.; project administration, M.L.; funding acquisition, M.L. All authors have read and agreed to the published version of the manuscript. 
Funding: This research was supported, in part, through the use of high-performance computing (HPC) resources and services provided by Technology Services at Tulane University, New Orleans, LA.

Institutional Review Board Statement: Not applicable.

Informed Consent Statement: Not applicable.

Data Availability Statement: The data presented in this study are available on request from the corresponding author.

Acknowledgments: Y.L. thanks the interdisciplinary Ph.D. Program in Aging Studies at Tulane University for their support of this research.

Conflicts of Interest: The authors declare no conflict of interest.

\section{References}

1. Taylor, J.T.; Huang, L.; Pottle, J.E.; Liu, K.; Yang, Y.; Zeng, X.; Keyser, B.M.; Agrawal, K.C.; Hansen, J.B.; Li, M. Selective blockade of T-type Ca2+ channels suppresses human breast cancer cell proliferation. Cancer Lett. 2008, 267, 116-124. [CrossRef]

2. Keyser, B.M.; Taylor, J.T.; Choi, S.K.; Lu, Y.; Bhattacharjee, A. Role of T-type Ca 2+ channels in basal [Ca 2+] i regulation and basal insulin secretion in rat islet cells. Curr. Trend Endocrinol. 2014, 7, 35-44.

3. Lu, Y.; Long, M.; Zhou, S.; Xu, Z.; Hu, F.; Li, M. Mibefradil reduces blood glucose concentration in db/db mice. Clinics 2014, 69, 61-67. [CrossRef]

4. Pottle, J.; Sun, C.; Gray, L.; Li, M. Exploiting MCF-7 Cells' Calcium Dependence with Interlaced Therapy. J. Cancer Ther. 2013, 4, 32-40. [CrossRef]

5. Dogrul, A.; Gardell, L.R.; Ossipov, M.H.; Tulunay, F.C.; Lai, J.; Porreca, F. Reversal of experimental neuropathic pain by T-type calcium channel blockers. Pain 2003, 105, 159-168. [CrossRef]

6. Li, M. Role of T-Type Ca2+ Channels in Basal Insulin Release. In T-Type Calcium Channels in Basic and Clinical Science; Springer: Berlin/Heidelberg, Germany, 2015; pp. 137-150.

7. Cribbs, L. T-type calcium channel expression and function in the diseased heart. Channels (Austin) 2010, 4, 447-452. [CrossRef]

8. Zhao, Y.; Huang, G.; Wu, Q.; Wu, K.; Li, R.; Lei, J.; Pan, X.; Yan, N. Cryo-EM structures of apo and antagonist-bound human Ca v 3.1. Nature 2019, 576, 492-497. [CrossRef] [PubMed]

9. Tang, L.; El-Din, T.M.G.; Swanson, T.M.; Pryde, D.C.; Scheuer, T.; Zheng, N.; Catterall, W.A. Structural basis for inhibition of a voltage-gated $\mathrm{Ca}(2+)$ channel by $\mathrm{Ca}(2+)$ antagonist drugs. Nature 2016, 537, 117-121. [CrossRef]

10. Li, Z.Q.; Scheraga, H.A. Monte-Carlo-Minimization Approach to the Multiple-Minima Problem in Protein Folding. Prac. Natl. Acad. Sci. USA 1987, 84, 6611-6615. [CrossRef]

11. Zhorov, B.S. Vector Method for Calculating the Derivatives of the Energy of Deformation of the Valence Angles and the Torsional Energy of Complex-Molecules with Respect to Generalized Coordinates. J. Struct. Chem. 1982, 23, 649-655. [CrossRef]

12. Zhorov, B.S. A Vector Method for Calculating the Derivatives of the Energy of the Atom-Atom Interactions of Complex-Molecules with Respect to Generalized Coordinates. J. Struct. Chem. 1981, 22, 4-8. [CrossRef]

13. Trott, O.; Olson, A.J. Software News and Update AutoDock Vina: Improving the Speed and Accuracy of Docking with a New Scoring Function, Efficient Optimization, and Multithreading. J. Comput. Chem. 2010, 31, 455-461. [PubMed]

14. Li, M.; Hansen, J.B.; Huang, L.; Keyser, B.M.; Taylor, J.T. Towards selective antagonists of T-type calcium channels: Design, characterization and potential applications of NNC 55-0396. Cardiovasc. Drug Rev. 2005, 23, 173-196. [CrossRef] [PubMed]

15. Cheng, R.C.K.; Tikhonov, D.B.; Zhorov, B.S. Structural Model for Phenylalkylamine Binding to L-type Calcium Channels. J. Biol. Chem. 2009, 284, 28332-28342. [CrossRef] [PubMed]

16. Li, S.C.; Ng, Y.K. Calibur: A tool for clustering large numbers of protein decoys. BMC Bioinform. 2010, 11, 25. [CrossRef] [PubMed]

17. Song, Y.; DiMaio, F.; Wang, R.Y.-R.; Kim, D.; Miles, C.; Brunette, T.; Thompson, J.; Baker, D. High-resolution comparative modeling with RosettaCM. Structure 2013, 21, 1735-1742. [CrossRef]

18. Hosseinzadeh, P.; Bhardwaj, G.; Mulligan, V.K.; Shortridge, M.D.; Craven, T.W.; Pardo-Avila, F.; Retti, S.A.; Kim, D.E.; Silva, D.A.; Ibrahim, Y.M.; et al. Comprehensive computational design of ordered peptide macrocycles. Science 2017, 358, 1461-1466. [CrossRef]

19. Cooper, C.D.; Barba, L.A. Poisson-Boltzmann model for protein-surface electrostatic interactions and grid-convergence study using the PyGBe code. Comput. Phys. Commun. 2016, 202, 23-32. [CrossRef]

20. Wu, S.W.; Zhang, M.; Vest, P.A.; Bhattacharjee, A.; Liu, L.; Li, M. A mibefradil metabolite is a potent intracellular blocker of L-type Ca2+ currents in pancreatic beta-cells. J. Pharmacol. Exp. Ther. 2000, 292, 939-943.

21. Gomez-Bombarelli, R.; Wei, J.N.; Duvenaud, D.; Hernandez-Lobato, J.M.; Sanchez-Lengeling, B.; Sheberla, D.; AguileraIparraguirre, J.; Hirzel, T.D.; Adams, R.P.; Aspuru-Guzik, A. Automatic Chemical Design Using a Data-Driven Continuous Representation of Molecules. ACS Central Sci. 2018, 4, 268-276. [CrossRef]

22. Tang, L.; Gamal El-Din, T.M.; Payandeh, J.; Martinez, G.Q.; Heard, T.M.; Scheuer, T.; Zheng, N.; Catterall, W.A. Structural basis for Ca2+ selectivity of a voltage-gated calcium channel. Nature 2014, 505, 56-61. [CrossRef] [PubMed] 
23. Hockerman, G.H.; Peterson, B.Z.; Johnson, B.D.; Catterall, W.A. Molecular determinants of drug binding and action on L-type calcium channels. Annu. Rev. Pharmacol. Toxicol. 1997, 37, 361-396. [CrossRef]

24. Peterson, B.Z.; Tanada, T.N.; Catterall, W.A. Molecular determinants of high affinity dihydropyridine binding in L-type calcium channels. J. Biol. Chem. 1996, 271, 5293-5296. [CrossRef] [PubMed]

25. Hockerman, G.H.; Johnson, B.D.; Scheuer, T.; Catterall, W.A. Molecular Determinants of High-Affinity Phenylalkylamine Block of L-Type Calcium Channels. J. Biol. Chem. 1995, 270, 22119-22122. [CrossRef]

26. Catterall, W.A.; Striessnig, J. Receptor-Sites for Ca2+ Channel Antagonists. Trends Pharmacol. Sci. 1992, 13, 256-262. [CrossRef]

27. Barreiro, G.; Guimarães, C.R.W.; de Alencastro, R.B. A molecular dynamics study of an L-type calcium channel model. Protein Eng. 2002, 15, 109-122. [CrossRef] [PubMed]

28. Chodera, J.D.; Mobley, D.L.; Shirts, M.R.; Dixon, R.W.; Branson, K.; Pande, V.S. Alchemical free energy methods for drug discovery: Progress and challenges. Curr. Opin. Struct. Biol. 2011, 21, 150-160. [CrossRef] [PubMed]

29. Wang, E.; Sun, H.; Wang, J.; Wang, Z.; Liu, H.; Zhang, J.Z.H.; Hou, T. End-Point Binding Free Energy Calculation with MM/PBSA and MM/GBSA: Strategies and Applications in Drug Design. Chem. Rev. 2019, 119, 9478-9508. [CrossRef]

30. Shapovalov, M.V.; Wang, Q.; Xu, Q.F.; Andrake, M.; Dunbrack, R.L. BioAssemblyModeler (BAM): User-Friendly Homology Modeling of Protein Homo- and Heterooligomers. PLoS ONE 2014, 9, e98309. [CrossRef]

31. Sanner, M.F.; Olson, A.J.; Spehner, J.C. Reduced surface: An efficient way to compute molecular surfaces. Biopolymers 1996, 38, 305-320. [CrossRef]

32. Kim, D.E.; Chivian, D.; Baker, D. Protein structure prediction and analysis using the Robetta server. Nucleic Acids Res. 2004, 32, W526-W531. [CrossRef]

33. Ertl, P.; Schuffenhauer, A. Estimation of synthetic accessibility score of drug-like molecules based on molecular complexity and fragment contributions. J. Cheminformatics 2009, 1, 8. [CrossRef] [PubMed]

34. Bickerton, G.R.; Paolini, G.V.; Besnard, J.; Muresan, S.; Hopkins, A.L. Quantifying the chemical beauty of drugs. Nat. Chem. 2012, 4, 90-98. [CrossRef] [PubMed]

35. Leite, T.B.; Gomes, D.; Miteva, M.A.; Chomilier, J.; Villoutreix, B.O.; Tuffery, P. Frog: A FRee Online druG 3D conformation generator. Nucleic Acids Res. 2007, 35, W568-W572. [CrossRef] [PubMed]

36. Miteva, M.A.; Guyon, F.; Tuffery, P. Frog2: Efficient 3D conformation ensemble generator for small compounds. Nucleic Acids Res. 2010, 38, W622-W627. [CrossRef]

37. O’Boyle, N.M.; Banck, M.; James, C.A.; Morley, C.; Vandermeersch, T.; Hutchison, G.R. Open Babel: An open chemical toolbox. J. Cheminformatics 2011, 3, 33. [CrossRef]

38. Laskowski, R.A.; Swindells, M.B. LigPlot+: Multiple Ligand-Protein Interaction Diagrams for Drug Discovery. J. Chem. Inf. Model. 2011, 51, 2778-2786. [CrossRef] 